УДК 616.72-002.77-085

DOI https://doi.org/10.11603/2312-0967.2020.4.11540

\title{
ТЕНДЕНЦІЇ ФАРМАКОЕПІДЕМІОЛОГІЇ РЕВМАТОЇДНОГО АРТРИТУ
}

\author{
Н. Л. Ханик ${ }^{1}$, О. Р. Левицька ${ }^{1}$, Г. І. Білущак², І. Я. Городецька ${ }^{1}$, Т. Я. Ханик \\ Львівський національний медичний університет імені Данила Галицького ${ }^{1}$ \\ Національний університет «Львівська політехніка» ${ }^{2}$ \\ Харківський національний медичний університет ${ }^{3}$ \\ herbolka@yahoo.com,levytska.oksana@gmail.com,gbilushak@gmail.com, \\ horodetska@gmail.com, taras.hanyk@gmail.com
}

\section{ІНФОРМАЦІЯ}

Надійшла до редакції / Received: 09.10 .2020

Після доопрацювання / Revised: 09.11 .2020

Прийнято до друку / Accepted: 12.11.2020

\section{Ключові слова:}

ревматоїдний артрит;

срармакотерапія;

схеми лікування.
АНОТАЦІЯ

Мета роботи. Порівняльний аналіз призначень лікарських засобів (ЛЗ) для фрармакотерапії (ФТ) хворих із ревматоїдним артритом (РА) в умовах закладу охорони здоров'я стаціонарного типу (3ОЗст) у 2009 та 2019 рр. і встановлення впливу чинних медико-технологічних документів на структуру таких призначень.

Матеріали і методи. Об'єктами дослідження були медичні карти і листки лікарських призначень (ЛЛП) 89 та 108 стаціонарних хворих 3 РА, котрі знаходилися на лікуванні у ревматологічному відділенні комунального некомерційного підприємства «4-а міська клінічна лікарня міста Львова» (КНП «4 МКЛ м. Львова») у 2009 та 2019 рр. відповідно. У роботі використовували методи: інформаційного пошуку, частотного, порівняльного, контент-аналізів, узагальнення даних та кластерного аналізу.

Результати й обговорення. Контент-аналіз ллп дозволив установити, що для ФТ РА використовувались ЛЗ трьох груп: хворобомодифікуючі протиревматичні препарати (ХМПРП), глюкокортикостероїди (ГКС) та нестероїдні протизапальні лікарські засоби (НПЗЛЗ). За досліджуваний період значно зросла частка призначень ХМПРП і знизилася - НПЗЛЗ. Порівняльний аналіз схем призначень ФТ РА засвідчив збільшення частки призначень тих схем лікування, де використовують ХМПРП, що відповідає вимогам чинного клінічного протоколу медичної допомоги хворим 3 PА. На підставі кластерного аналізу 24 міжнародних непатентованих назв (МНH) Л3 за частотою їх призначень виділено три групи Л3. Перша - препарати, які не призначались у 2019 р.; друга - препарати-лідери за призначуваністю; третя - Лз із середнім та низьким рівнем призначуваності.

Висновки. Проведений аналіз призначень ХМПРП, НПЗЛЗ та ГКС для орармакотерапії РА показав вагомий вплив клінічних протоколів на вибір тактики лікування РА. Кластерний аналіз дозволив розбити Лз на групи та визначити найперспективніші ЛЗ для лікування РА.
Вступ. РА - це хронічне захворювання суглобів, спричинене змінами в імунній системі, яке спостерігається в 1 \% населення земної кулі.
Саме ця хвороба є однією з найчастіших причин інвалідності як в Україні, так і у світі. Смертність у пацієнтів з РА вища у 2,5 раза порівняно 3 осо-

ISSN 2312-0967. Pharmaceutical review. 2020. № 4 
бами тієї ж статі й віку, що не страждають на це захворювання [1].

Серед наукових робіт, що тісно пов'язані з вивченням питання приймання лікарських засобів (ЛЗ), призначених для ФТ РА, можна виділити публікації, які стосуються аналізу асортименту лз для лікування РА та його аналітичної оцінки [2-5], оптимізації медикаментозної допомоги хворим на РА [6]. Дослідники обґрунтовували важливість індивідуальних підходів до пацієнтів з РА при призначенні ФТ [7], вивчали відповідність стаціонарного етапу лікування РА положенням галузевих стандартів [8], асортимент, економічну доступність та обсяги споживання НПЗЛЗ на срармацевтичному ринку України [9]. Крім того, досліджували український фрармацевтичний ринок препаратів для лікування артриту [10]. У попередніх дослідженнях ми аналізували споживання Л3 хворими 3 РА у двох 3ОЗст Львівської та Тернопільської областей [11] та порівнювали асортимент ЛЗ для ФТ РА в Україні та Великій Британії [12].

ФТ РА регламентувалася двома медико-технологічними документами. До 2014 р. - клінічним протоколом надання медичної допомоги хворим з РА, затвердженим наказом Міністерства охорони здоров'я (МО3) України № 676 від 12.10.2006 р. [13], а з 2014 р. - уніфрікованим клінічним протоколом первинної, вторинної (спеціалізованої), третинної (високоспеціалізованої) медичної допомоги та медичної реабілітації для РА, який затверджений наказом МОЗ України № 263 від 11.04.2014 р. [14].

Порівняння положень клінічних протоколів медичної допомоги хворим з РА за 2006 та 2014 рр. у частині фрармакотерапії цього захворювання показало, що для лікування РА у першому медико-технологічному документі рекомендовано включати такі лЗ: НПЗЛ3, базисну терапію (ЛЗ, які безпосередньо впливають на імунопатологічний процес, відповідальний за розвиток артриту, а саме: препарати золота, антиметаболіти, салазо-сульфаніламідні препарати, циклоспорини та амінохінолонові препарати), біологічні агенти (БА), ГКС та препарати системної ензимотерапії. Монотерапію НПЗЛЗ призначали при активності запального процесу І ступеня, переважно неімунному механізмі запалення, перебігу ревматоїдного процесу, який повільно прогресує, чи відсутності системних проявів хвороби. У всіх інших випадках була рекомендована комбінована терапія 3 використанням НПЗЛЗ та вказаних вище груп ЛЗ [13].

У другому медико-технологічному документі (2014 р.) для означення базисних Лз використовується термін «синтетичні ХМПРП», які вважаються препаратами першої лінії для ФТ РА. Крім того, призначають ГКС і БА. Вважається, що комбінована базисна терапія $€$ ефрективнішою порівняно з монотерапією. Згідно з цим клінічним протоколом НПЗЛЗ та анальгетики рекомендовано призначати лише з ме- тою симптоматичної знеболювальної та протизапальної терапії [14]. Таким чином, прослідковується зміна вимог до призначень ЛЗ хворим з РА. Тому актуальним $€$ дослідження фрармакоепідеміології РА та впливу чинного медико-технологічного документа на структуру призначень ЛЗ хворим з РА.

Мета роботи. Порівняльний аналіз призначень ЛЗ для ФТ хворих із РА в умовах ЗОЗст у 2009 та 2019 рр. і встановлення впливу чинних медико-технологічних документів на структуру таких призначень.

Матеріали і методи. Об'єктами дослідження були медичні карти і листки лікарських призначень (ЛЛП) 89 та 108 стаціонарних хворих з РА, котрі знаходилися на лікуванні у ревматологічному відділенні комунального некомерційного підприємства «4-а міська клінічна лікарня міста Львова» (КНП «4 МКЛ м. Львова») у 2009 та 2019 рр. відповідно. У вибірки включено 65 жінок та 24 чоловіків у 2009 р. і 95 жінок та 13 чоловіків у 2019 р. Вік хворих у вибірках коливався від 18 до 80 (середній вік 55,3 року) та від 27 до 82 років (середній вік 57,5 року) у 2009 і 2019 рр. відповідно. У роботі використовували методи: інформаційного пошуку, частотного, порівняльного, контент-аналізів, узагальнення даних та кластерного аналізу. Обробку даних проводили за допомогою пакету прикладних програм Microsoft Excel.

Результати й обговорення. У досліджуваному 3ОЗст для лікування РА використовували такі групи Л3: синтетичні ХМПРП, ГКС та НПЗЛЗ, поєднання яких фрормує шість схем ФТ РА (рис. 1).

Порівняльний аналіз схем призначень ФТ РА в аналізованому ЗОЗст у 2009 та 2019 рр. показав збільшення кількості призначень схеми лікування, яка включала ХМПРП, ГКС та НПЗЛЗ з 42,7\% до $52,8 \%$ (рис. 1). Також спостерігається тенденція збільшення частки призначень схеми поєднання ХМПРП та НПЗЛЗ з 16,9 \% до 25,9 \%. У 2 та 4,8 раза відповідно зменшилася кількість використання схеми поєднання ГКС з НПЗЛЗ та монотерапії НПЗЛЗ. 3 2009 р. по 2019 р. незначно зросла частка призначень схем лікування, у яких використовують ХМПРП і ГКС та монотерапії ХМПРП. Отже, спостерігається збільшення частки призначень тих схем лікування, де використовують ХМПРП, що і рекомендується клінічним протоколом медичної допомоги хворим з РА.

Контент-аналіз ЛЛП дозволив установити, що для ФТ РА використовувались ЛЗ трьох груп: ХМПРП, ГКС та НПЗЛЗ. Призначення ХМПРП у 2009 р. становило $18,1 \%$, а у 2019 р. $25,4 \%$, ГКС - $26,8 \%$ та $29,3 \%$, а НПЗЛ3 - 55,1\% та 45,3\% відповідно (табл. 1).

За аналізований період серед ХМПРП кількісно збільшилася частка призначень метотрексату, однак його процентне співвідношення щодо інших представників цієї групи зменшилося через приріст у застосуванні лз із лефлуномідом і сульфосалазином. У 2019 р. лікарі більше не призначали ЛЗ з гідроксихлорохіном та хлорохіном.

ISSN 2312-0967. Фармацевтичний часопис. 2020. № 4 


\section{• ХМПРП/ГКС/НПЗЛЗ \\ - ХМПРП/НПЗЛЗ \\ - ХМПРП/ГКС}

\section{- ГКС/НПЗЛЗ \\ - НПЗЛЗ \\ 口 ХМПРП}

Рис. 1. Розподіл схем ФТ РА за кількістю призначень у досліджуваному зОзст (у \%).

Таблиця 1

Позиціонування призначень ХМПРП у досліджуваному ЗОЗст у 2009 та 2019 рр.

\begin{tabular}{|c|c|c|c|c|c|}
\hline \multirow{3}{*}{ АТХ код } & \multirow{3}{*}{ Діюча речовина } & \multicolumn{2}{|c|}{2009} & \multicolumn{2}{|c|}{2019} \\
\hline & & \multicolumn{2}{|c|}{ к-сть призначень } & \multicolumn{2}{|c|}{ к-сть призначень } \\
\hline & & од. & $\%$ & од. & $\%$ \\
\hline \multicolumn{2}{|l|}{ ХМПРП } & 60 & 18,1 & 100 & 25,4 \\
\hline L01B A01 & Метотрексат & 43 & 71,7 & 56 & 56,0 \\
\hline P01B A02 & Гідроксихлорохін & 7 & 11,7 & - & - \\
\hline P01B A01 & Хлорохін & 6 & 10,0 & - & - \\
\hline L04A A13 & Леорлуномід & 4 & 6,7 & 36 & 36,0 \\
\hline A07E C01 & Сульфрасалазин & - & - & 8 & 8,0 \\
\hline \multicolumn{2}{|l|}{ ГКС } & 89 & 26,8 & 115 & 29,3 \\
\hline H02A B04 & Метилпреднізолон & 48 & 53,9 & 92 & 80,0 \\
\hline H02A B02 & Дексаметазон & 31 & 34,8 & 14 & 12,2 \\
\hline H02A B01 & Бетаметазон & 6 & 6,7 & 7 & 6,1 \\
\hline H02A B06 & Преднізолон & 4 & 4,5 & 2 & 1,7 \\
\hline \multicolumn{2}{|l|}{ НПЗлЗ } & 183 & 55,1 & 178 & 45,3 \\
\hline M01A C06 & Мелоксикам & 54 & 29,5 & 56 & 31,5 \\
\hline M01A B05 & Диклофенак & 66 & 36,1 & 49 & 27,5 \\
\hline M01A C02 & Теноксикам & - & - & 40 & 22,5 \\
\hline M01A C05 & Лорноксикам & 3 & 1,6 & 7 & 3,9 \\
\hline M01A B55 & Диклофенак, комб. & 8 & 4,4 & 5 & 2,8 \\
\hline M01A E17 & Декскетопрофрен & 7 & 3,8 & 5 & 2,8 \\
\hline M01A B16 & Ацеклофренак & 2 & 1,1 & 4 & 2,2 \\
\hline M01A E01 & Ібупрофрен & - & - & 4 & 2,2 \\
\hline M01A B15 & Кеторолак & 18 & 9,8 & 3 & 1,7 \\
\hline M01A H01 & Целекоксиб & 5 & 2,7 & 2 & 1,1 \\
\hline M01A E02 & Напроксен & - & - & 1 & 0,6 \\
\hline M02A A26 & Німесулід & 7 & 3,8 & 1 & 0,6 \\
\hline M01A X67 & Німесулід, комб. & 1 & 0,5 & 1 & 0,6 \\
\hline M01A H02 & Рофрекоксиб & 8 & 4,4 & - & - \\
\hline M02A A10 & Кетопрофрен & 4 & 2,2 & - & - \\
\hline
\end{tabular}

ISSN 2312-0967. Pharmaceutical review. 2020. № 4 
Основні тенденції призначення різних ГКС у 2009 та 2019 рр. показали зменшення частки застосування л3 із дексаметазоном (3 34,8 \% до 12,2\%), бетаметазоном (з 6,7 \% до 6,1\%) та преднізолоном (3 4,5 \% до 1,7 \%), а також збільшення частки використання Л3 з метилпреднізолоном (з 53,9 \% до 80,0\%).

У 2019 р. збільшується кількість призначень НПЗЛЗ із теноксикамом (у 2009 р. не призначали), лорноксикамом (з 1,6\% до 3,9\%), ацеклофенаком (3 1,1 \% до 2,2 \%) та мелоксикамом (29,5 \% до 31,5 \%). У 2019 р. з НПЗЛЗ почали інтенсивно призначати теноксикам. Зменшилася частка застосувань Лз із кеторолаком (з 9,8 \% до 1,7\%), целекоксибом (3 2,7 \% до 1,1 \%), німесулідом (із 3,8 \% до 0,6\%), диклосенаком у комб. (з 4,4 \% до 2,8 \%) та декскетопрофеном (з 3,8 \% до 2,8 \%). Перестали призначати НПЗЛ3 із рофрекоксибом та кетопрофеном.

На рисунку 2 представлено динаміку призначень у досліджуваному ЗОЗст НПЗЛЗ за їх селективністю. Позицію лідера за кількістю призначень займали неселективні НПЗЛЗ. У 2019 р. їхня частка у 1,8 раза переважала частку застосування селективних НПЗЛЗ. У 2009 р. частка призначень неселективних була у 1,4 раза більша, ніж селективних. Як зазначалося у наших попередніх дослідженнях [15], це співвідношення з 2003 по 2010 рр. скорочувалося на користь селективних НПЗЛЗ. Так, у 2003 р. воно становило один до п'яти на користь неселективних, однак тепер спостерігається протилежна тенденція.

Отже, в досліджуваному ЗОЗст за аналізований період призначали п'ять МНН ХМПРП, чотири ГКС та п'ятнадцять НПЗЛЗ. За результатами проведеного нами кластерного аналізу цих ЛЗ у 2009 та 2019 рр. 24 МНН відповідно до кількості призначень було виокремлено на три кластери (табл. 2).

До першого кластеру увійшли ті ЛЗ, які призначали лише у 2009 р. та не застосовували у 2019 р. Це гідроксихлорохін і хлорохін з ХМПРП та рофекоксиб і кетопрофен з НПЗЛЗ.

Згідно 3 клінічним протоколом лікування РА за 2014 р. Л3 із хлорохіном немає в переліку ХМПРП для ФТ РА [14]. Л3 із гідроксихлорохіном рекомендують призначати у комплексній терапії разом з іншими ХМПРП [14]. Обидва препарати доцільно застосовувати при ранніх стадіях РА з низьким ступенем активності, оскільки вони показали нижчу клінічну ефективність порівняно з метотрексатом, який є препаратом першої лінії для лікування РА [16]. Цим, можливо, пояснюється відсутність даних ЛЗ у призначеннях 2019 p.

Л3 рофекоксиб (торгова назва (ТH) Віокс) ще у 2004 р. після 5 років застосування був відкликаний фрірмою-виробником препарату «Merck\&Co.» із фрармацевтичного ринку у США та країнах Європейського Союзу у зв'язку з високим рівнем серцево-судинного ризику при його застосуванні. Крім того, було рекомендовано фрірмам-виробникам генериків препарату припинити їх виробництво та продаж у світі [17]. Тому позитивним $є$ те, що рофекоксиб у 2019 р. в досліджуваному 30Зст не призначали. При цьому хочемо зауважити, що цей лз під іншою ТН зареєстрований в Україні і є на вітчизняному ринку.

Призначення кетопрофену у 2009 р. було незначним, а в 2019 р. цей Л3 взагалі не призначали. Причину такого явища ми пояснити не можемо.

До другого кластеру включено ЛЗ-лідери призначень у досліджуваному 3ОЗст. До них належать метотрексат з ХМПРП, метилпреднізолон з ГКС та мелоксикам і диклофенак з НПЗЛЗ. Метотрексат є препаратом першого вибору на початковій стадії лікування РА, еорективність і безпека якого доведена у чисельних рандомізованих клінічних дослідженнях $[14,19]$. У протоколі ФТ РА не зазначають конкретних МНН ГКС, однак в досліджуваному 3ОЗст метилпреднізолон призначали найчастіше. Диклосренак, який залишається золотим стандартом для оцінки есрективності НПЗЛЗ [18] та мелоксикам, як представник селективних НПЗЛЗ, також входять до другого кластеру.

Третій кластер сорормували ті Л3, які хоча і призначали хворим на РА, однак вони мали середній або низький рівень призначуваності.

2019

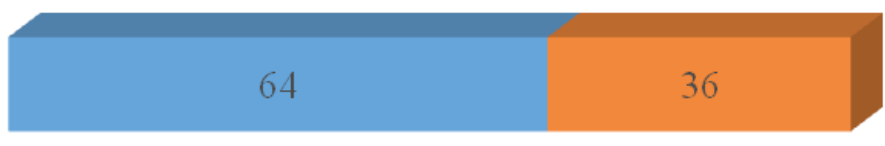

2009

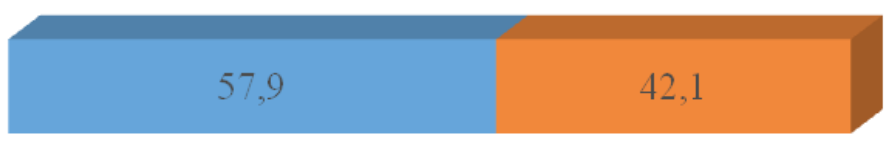

- Неселективні НПзл3 Селективні НПЗЛ3

Рис. 2. Кількість призначень неселективних і селективних НПЗЛЗ у 2009 та 2019 рр. (у \%).

ISSN 2312-0967. Фармацевтичний часопис. 2020. № 4 
Таблиця 2

Кластеризація лікарських засобів за кількістю призначень (\%)

\begin{tabular}{|c|c|c|c|}
\hline $\mathrm{MHH}$ & К-сть призначень 2009 р. & К-сть призначень 2019 р. & Кластер \\
\hline Гідроксихлорохін & 11,7 & - & 1 \\
\hline Хлорохін & 10,0 & - & 1 \\
\hline Рофрекоксиб & 4,4 & - & 1 \\
\hline Кетопрофрен & 2,2 & - & 1 \\
\hline Метотрексат & 71,7 & 56,0 & 2 \\
\hline Метилпреднізолон & 53,9 & 80,0 & 2 \\
\hline Мелоксикам & 29,5 & 31,5 & 2 \\
\hline Диклофренак & 36,1 & 27,5 & 2 \\
\hline Лесрлуномід & 6,7 & 36,0 & 3 \\
\hline Сульфрасалазин & 0 & 8,0 & 3 \\
\hline Дексаметазон & 34,8 & 12,2 & 3 \\
\hline Бетаметазон & 6,7 & 6,1 & 3 \\
\hline Преднізолон & 4,5 & 1,7 & 3 \\
\hline Теноксикам & 0 & 22,5 & 3 \\
\hline Лорноксикам & 1,6 & 3,9 & 3 \\
\hline Диклосренак, комб. & 4,4 & 2,8 & 3 \\
\hline Декскетопрофрен & 3,8 & 2,8 & 3 \\
\hline Ацеклофенак & 1,1 & 2,2 & 3 \\
\hline Ібупросрен & 0 & 2,2 & 3 \\
\hline Кеторолак & 9,8 & 1,7 & 3 \\
\hline Целекоксиб & 2,7 & 1,1 & 3 \\
\hline Напроксен & 0 & 0,6 & 3 \\
\hline Німесулід & 3,8 & 0,6 & 3 \\
\hline Німесулід, комб. & 0,5 & 0,6 & 3 \\
\hline
\end{tabular}

Висновки. Проведений аналіз призначень ХМПРП, НПЗЛЗ та ГКС для ФТ РА показав вагомий вплив клінічних протоколів на вибір тактики лікування РА. Кластерний аналіз дозволив розбити лЗ на групи та визначити найперспективніші ЛЗ для ФТ РА. Конфлікт інтересів: відсутній.

Conflict of interest: authors have no conflict of interest to declare.

\section{TRENDS IN PHARMACOEPIDEMIOLOGY OF RHEUMATOID ARTHRITIS}

\section{N. L. Khanyk ${ }^{1}$, O. R Levytska ${ }^{1}$, H. I. Bilushchak ${ }^{2}$, I. Ya. Horodetska ${ }^{1}$, T. Ya. Khanyk ${ }^{3}$}

Danylo Halytsky Lviv National Medical University ${ }^{1}$

Lviv Polytechnic National University²

Kharkiv National Medical University ${ }^{3}$

herbolka@yahoo.com,levytska.oksana@gmail.com,gbilushak@gmail.com,horodetska@gmail.com, taras.hanyk@gmail.com

The aim of the work. Comparative analysis of the pharmacotherapy of patients with rheumatoid arthritis (RA) in a health care institution and estimation of the impact of existing treatment protocol on the drugs prescribing.

Materials and Methods. The object of the study were medical cards and medical records of 89 and 108 inpatients with RA, who were treated in the Rheumatology Department of the City Clinical Hospital of Lviv No. 4 in 2009 and 2019 correspondingly. Methods of data retrieval, frequency, comparative, content analysis, data aggregation and cluster analysis were used.

ISSN 2312-0967. Pharmaceutical review. 2020. № 4 
Results and Discussion. Content analysis of medical records revealed that three groups of drugs were used for the pharmacotherapy of RA. They were disease-modifying antirheumatic drugs (DMARDs), glucocorticosteroids (GCS) and nonsteroidal anti-inflammatory drugs (NSAIDs). During the analysed period, the share of DMARDs prescribing significantly increased and the share of NSAIDs indications decreased. Comparative analysis of the schemes of pharmacotherapy of patients with RA allowed establishing an increase in the share of prescribing of those treatment schemes that use DMARDs, which meets the requirements of the current clinical protocol of medical care for patients with RA. Based on the cluster analysis of 24 international non-proprietary names of drugs, three groups of them were identified according to the frequency of their prescribing. To the first group belonged drugs that were not prescribed in 2019. The second and third groups included drugs - leaders and drugs with medium and low level of prescribing correspondingly.

Conclusions. The analysis of prescribed DMARDs, GCS and NSAIDs for RA pharmacotherapy showed a significant influence of clinical protocols on the choice of RA treatment tactics. Cluster analysis allowed dividing drugs into groups and identifying the most perspective drugs for the RA treatment.

Key words: rheumatoid arthritis; pharmacotherapy; treatment schemes.

\title{
ТЕНДЕНЦИИ ФАРМАКОЭПИДЕМИОЛОГИИ РЕВМАТОИДНОГО АРТРИТА
}

\author{
Н. Л. Ханык ${ }^{1}$, О. Р. Левицкая ${ }^{1}$, Г. И. Билущак², И. Я. Городецкая ${ }^{1}$, Т. Я. Ханык \\ Львовский национальный медицинский университет имени Данила Галицкого ${ }^{1}$
}

Национальный университет «Львовская политехника» ${ }^{2}$

Харьковский национальный медицинский университет ${ }^{3}$

herbolka@yahoo.com, levytska.oksana@gmail.com,gbilushak@gmail.com, horodetska@gmail.com, taras.hanyk@ gmail.com

Цель работы. Сравнительный анализ назначений лекарственных средств (ЛС) для срармакотерапии (ФТ) больных с ревматоидным артритом (РА) в условиях учреждения здравоохранения стационарного типа в 2009 и 2019 гг. и установление влияния действующих медико-технологических документов на структуру таких назначений.

Материалы и методы. Объектом исследования были медицинские карты и листы врачебных назначений (ЛВН) 89 и 108 стационарных больных с РА, которые находились на лечении в ревматологическом отделении коммунального некоммерческого предприятия «4-я городская клиническая больница города Львова» в 2009 и 2019 гг. соответственно. В работе использовали методы: информационного поиска, частотного, сравнительного, контент-анализов, обобщения данных и кластерного анализа.

Результаты и обсуждение. Контент-анализ ЛВН позволил установить, что для ФТ РА использовались ЛС трех групп: болезнь-модисрицирующие антиревматические препараты (БМАРП), глюкокортикостероиды (ГКС) и нестероидные противовоспалительные препараты (НПВП). За исследуемый период значительно выросла доля назначений БМАРП и снизилась - НПВП. Сравнительный анализ схем назначений ФТ РА позволил установить увеличение доли назначений тех схем лечения, где используют БМАРП, что соответствует требованиям действующего клинического протокола медицинской помощи больным с РА. На основании кластерного анализа 24 международных непатентованных названий лекарств по частоте их назначений, выделено три группы ЛС. Первая - препараты, которые не назначались в 2019 г.; вторая - препараты-лидеры по назначениям; третья - ЛС со средним и низким уровнем назначений.

Выводы. Проведенный анализ назначений БМАРП, ГКС и НПВП для фрармакотерапии РА показал существенное влияние клинических протоколов на выбор тактики лечения РА. Кластерный анализ позволил разбить ЛС на группы и определить перспективные лС для лечения РА.

Ключевые слова: ревматоидный артрит; фрармакотерапия; схемы лечения.

\section{Список бібліографрічних посилань}

1. Поник Р. М., Коритко 3. І. Захворюваність та особливості реабілітації хворих на ревматоїдний артрит в умовах сьогодення. Здобут. клін. і експерим. мед. 2019. № 3. С. 183-187.

2. Бакалец Н. Ф., Никифорова О. П. Аналитическая оценка амбулаторного лечения пациентов с ревматоидным артритом. Проблемы здоровья и экологии. 2016. № 4 (50). URL: https://cyberleninka. ru/article/n/analiticheskaya-otsenka-ambulatornogolecheniya-patsientov-s-revmatoidnym-artritom/viewer

3. Анализ общего ассортимента лекарственных препаратов, применяемых для лечения ревматоидного артрита развернутой стадии и его осложнений в стационаре / Т. И. Оконенко, А. К. Хруцкий, Л. Б. Оконенко, А. В. Иванова. Вестник НовГУ. 2016. № 6 (97). С. 95-99.

ISSN 2312-0967. Фармацевтичний часопис. 2020. № 4 
4. Оконенко Т. И., Хруцкий А. К., Егорова Е. С. Заболеваемость населения Новгородской области ревматоидным артритом и анализ базисной терапии. Здоровье и образование в XXI веке. 2016. URL: https://cyberleninka.ru/article/n/zabolevaemostnaseleniya-novgorodskoy-oblasti-revmatoidnym-artritom-i-analiz-bazisnoy-terapii/viewer

5. Чичасова Н. В. Ревматоидный артрит: проблемь лечения на современном этапе. Современная ревматология. 2018. № 4. С. 65-70.

6. Зинчук И. Ю. Оптимизация лекарственной помощи больным ревматоидным артритом на основе фрармакоэкономических исследований : автореф. дис. на здобуття наук. ступеня канд. фрармац. наук : 14.04.03. Москва, 2013. 24 с.

7. Рудюк Л. І., Харітонова О. М. Фармакотерапія при ревматоїдному артриті : сучасний погляд на проблему. Укр. ревматол. журн. 2013. № 4. С. 46-49.

8. Kyrychenko O. M., Hyzhka Ye. I. The assessment of compliance of the inpatient stage pharmacotherapy when treating rheumatoid arthritis with provisions of industry standards. Clinical Pharmacy. 2016. Vol. 20. P. 38-41. DOI: https://doi.org/10.24959/cphj.16.1389.

9. Яковлєва Л. В., Тітова А. А. Дослідження асортименту групи лікарських засобів НПЗ3 на фрармацевтичному ринку в Україні за період 20142018 років. Фармац. журн. 2019. № 4. C. 41-51. DOI: 10.32352/0367-3057.4.19.05

10. Postoy V. V., Vyshnevska L. I. The marketing research of the Ukrainian market of drugs for the treatment of arthritis. Вісник фрармації. 2018. № 1 (93). P. 38-42. DOI: 10.24959/nphj.18.2198

11. Герболка-Ханик Н. Л., Левицька О. Р. Аналіз споживання лікарських засобів для основної фрармакотерапії хворих з ревматоїдним артритом. Укр. мед. альманах. 2011. № 4. С. 58-60.

12. Герболка-Ханик Н. Л., Грушковська Д. Т., Борушевська Л. В. Порівняльний аналіз асортименту лікарських засобів для основної фрармакотерапії ревматоїдного артриту в Україні та Великій Британії.

\section{References}

1. Ponyk RM, Korytko ZI. [Disease and peculiarities of rehabilitation of patients with rheumatoid arthritis in the present time]. Zdobut kiln i eksperym med. 2019;3: 183-7. Ukrainian.

2. Bakalets NF, Nykyforova OP. [Analytical assessment of out-patient treatment of patients with rheumatoid arthritis]. Problemy zdorovya i ekologii. 2016;4(50). Available from: https://cyberleninka.ru/article/n/analiticheskaya-otsenka-ambulatornogo-lecheniya-patsientov-srevmatoidnym-artritom/viewer. Russian.

3. Okonenko TY, Khrutskyy AK, Okonenko LB, Yvanova AV. [Analysis of the total product line of medicines used to treat progressive rheumatoid arthritis and its complications in hospital]. Vestnyk NovGU. 2016;6(97): 95-9. Russian.

4. Okonenko TY, Khrutskiy AK, Ehorova ES. [Morbidity Novgorod region rheumatoid arthritis, an analysis of the basic treatment and information preferences].
Укр. мед. альманах. 2011. № 5. С. 47-49.

13. Про затвердження протоколів надання медичної допомоги за спеціальністю «Ревматологія» наказ МО3 України від 13.10.2006 р. № 676. URL: https://zakon.rada.gov.ua/rada/show/v0676282-06/ ed20061012\#Text (дата звернення: 15.03.2019)

14. Унісікований клінічний протокол первинної, вторинної (спеціалізованої), третинної (високоспеціалізованої) медичної допомоги та медичної реабілітації для ревматоїдного артриту : наказ МО3 України від 11.04.2014 р. № 263. URL: https://dec.gov. ua/wp-content/uploads/images/dodatki/2014_263_revmat_artryt/2014_263_YKPMD_RA.pdf (дата звернення: 15.03.2019)

15. ХаникН. Л. Організаційно-економічне обґрунтування рекомендацій 3 оптимізації медикаментозного забезпечення населення нестероїдними протизапальними лікарськими засобами : автореф. дис. на здобуття наук. ступеня канд. фрармац. наук: 15.00.01. Львів, 2009. 22 с.

16. Список препаратов нового поколения для лечения ревматоидного артрита. Подробная характеристика представителей. URL: https://sustav.med-ru.net/lechenie_sustavov/preparaty/spisok-p-novogo-pokoleniyadlya-I-revmatoidnogo-artrita-podrobnaya-harakteristika-predstavitelej.html

17. Бежчейко В. Порівняльна ефективність нестероїдних протизапальних препаратів (НПЗП). Психосоматична медицина та загальна практика. 2017. Tom 2. № 3. C. 1-3. URL: https://uk.e-medjournal.com/ index.php/psp/article/view/48/107

18. Шуба Н. М., Воронова Т. Д., Кокунов Ю. О. НПВПриски и выбор безопасной терапии. Укр. ревматол. журн. 2018. № 1 (71). С. 16-22.

19. Яременко О. Б., Івашківський О. І., Федьков Д. Л. Ефективність і переносимість імунобіологічної терапії у пацієнтів із ревматоїдним артритом. Укр. ревматол. журн. 2011. C. 1-7. URL: https://www.rheumatology.kiev.ua/wp/wp-content/uploads/2011/12/709. pdf?upload $=$

Health and Education Millennium. 2016. Available from: https://cyberleninka.ru/article/n/zabolevaemostnaseleniya-novgorodskoy-oblasti-revmatoidnym-artritom-i-analiz-bazisnoy-terapii/viewer. Russian.

5. Chichasova NV. [Rheumatoid arthritis: problems of treatment at the present stage]. Sovremennaya revmatologiya. 2018;4:65-70. Russian.

6. Zinchuk YYu. Optimization of medical care of patients with rheumatoid arthritis based on pharmacoeconomic research. Extended abstract of Candidate's thesis: 14.04.03. Moscow; 2013. 24 p. Russian.

7. Rudyuk LI, Kharitonova OM. [Pharmacotherapy of rheumatoid arthritis: a modern approach to the problem]. Ukr revmatol zhur. 2013;4: 46-9. Ukrainian.

8. Kyrychenko OM, Hyzhka Yel. The assessment of compliance of the inpatient stage pharmacotherapy when treating rheumatoid arthritis with provisions of industry

ISSN 2312-0967. Pharmaceutical review. 2020. № 4 
standards. Clinical pharmacy. 2016;20: 38-41. Available from: DOI: https://doi.org/10.24959/cphj.16.1389.

9. Yakovlyeva LV, Titova AA. [Research of medicina products of the NSAID of the pharmaceutical market in Ukraine for the period 2014-2018]. Farmatsev. zhurnal. 2019;4: 41-51. Ukrainian. Available from: DOI: 10.32352/0367-3057.4.19.05.

10. PostoyVV, Vyshnevska LI. The marketing research of the Ukrainian market of drugs for the treatment of arthritis. Visnyk farmatsii. 2018;1(93): 38-42. DOI: https:// doi.org/10.24959/cphj.16.1389.

11. Herbolka-Khanyk NL, Levytska OR. [Analysis of use of main drugs for treatment of patients with rheumatoid arthritis]. Ukr med almanakh. 2011;4: 58-60. Ukrainian.

12. Herbolka-Khanyk NL, Hrushkovska DT, Borushevska LV. Comparative analysis of the assortment of the main drugs used for rheumatoid arthritis treatment in Ukraine and Great Britain. Ukr med almanakh. 2011;5: 47-9. Ukrainian.

13. On approval of protocols for the provision of medical care in the specialty "Rheumatology". Order of the Ministry of Health of Ukraine dated 13.10.2006 № 676 . Ukrainian. Avaialble from: https://zakon.rada.gov.ua/ rada/show/v0676282-06/ed20061012\#Text.

14. Unified clinical protocol of primary, secondary (specialized), tertiary (highly specialized) medical care and medical rehabilitation for rheumatoid arthritis. Order of the Ministry of Health of Ukraine dated 11.04.2014 No. 263. Available from: https://dec.gov.ua/wp-content/uploads/images/dodatki/2014_263_revmat_artryt/2014 263 YKPMD RA.pdf. Ukrainian.

15. Khanyk NL. [Örganizational and economic substantiation of optimal medicamentous provision of population with non-steroidal anti-inflammatory drugs]. Extended abstract of Candidate's thesis: 15.00.01. Lviv; 2009. 22p. Ukrainian.

16. List of new generation drugs for the treatment of rheumatoid arthritis. Detailed characteristics of representatives. Available from: https://sustav.med-ru.net/lechenie_sustavov/preparaty/spisok-p-novogo-pokoleniyadlya-I-. Russian.

17. Bezhcheyko V. [Comparison of effectiveness of nonsteroidal anti-inflammatory drugs (NSAIDs)]. 2017;2(3): 1-3. Available from: https://uk.e-medjournal.com/index. php/psp/article/view/48/107. Ukrainian.

18. Shuba NM, Voronova TD, Kokunov YuO. [Risks of NSAIDS and safe therapy selection]. Ukr revmatol zhur. 2018;1(71): 16-22. Ukrainian.

19. Yaremenko OB, Ivashkovskyi OI, Fedkov DL. [The efficacy and tolerability of immunobiologic therapy in patients with rheumatoid arthritis] Ukr revmatol zhur. 2011. [Internet]. Available from: https://www.rheumatology.kiev.ua/wp/wp-content/uploads/2011/12/709. pdf?upload=. Ukrainian.

\section{Відомості про авторів}

Ханик Н. Л. - канд. фрармац. наук, доцент кафедри організації та економіки фармації Львівського національного медичного університету імені Данила Галицького, м. Львів, Україна. E-mail: herbolka@yahoo.com, ORCID 0000-00022166-0222.

Левицька О. Р. - канд. фрармац. наук, доцент кафедри організації та економіки фрармації Львівського національного медичного університету імені Данила Галицького, м. Львів, Україна. E-mail: levytska.oksana@gmail.com, ORCID 0000-0002-8113-2587.

Білущак Г. І. - канд. фріз-мат. наук, доцент кафедри обчислювальної математики та програмування Національного університету «Львівська Політехніка», Інституту прикладної математики та фрундаментальних наук, м. Львів, Україна. E-mail: gbilushak@gmail.com, ORCID 0000-0002-1226-8050.

Городецька І. Я. - канд. фрармац. наук, доцент кафедри організації та економіки фрармації Львівського національного медичного університету імені Данила Галицького, м. Львів, Україна. E-mail: horodetska@gmail.com, ORCID 00000003-0265-5505

Ханик Т. Я. - заочний аспірант каседри травматології та ортопедії Харківського національного медичного університету, м. Харків, Україна. E-mail: taras.hanyk@gmail.com, ORCID 0000-0003-1656-6239.

\section{Information about the authors}

Khanyk N. L. - PhD (Pharmacy), Associate Professor of the Department of Organization and Economics of Pharmacy, Lviv Danylo Halytsky National Medical University, Lviv, Ukraine. E-mail: herbolka@yahoo.com, ORCID 0000-0002-21660222.

Levytska O. R - PhD (Pharmacy), Associate Professor of the Department of Organization and Economics of Pharmacy, Lviv Danylo Halytsky National Medical University, Lviv, Ukraine. E-mail: levytska.oksana@gmail.com, ORCID 0000-00028113-2587.

Bilushchak H. I. - PhD (Physics and Mathematics), Associate Professor of the Department of Computational Mathematics and Programming, Institute of Applied Mathematics and Fundamental Sciences, Lviv Polytechnic National University, Lviv, Ukraine. E-mail: gbilushak@gmail.com, ORCID 0000-0002-1226-8050.

Horodetska I. Ya. - PhD (Pharmacy), Associate Professor of the Department of Organization and Economics of Pharmacy, Lviv Danylo Halytsky National Medical University, Lviv, Ukraine. E-mail: horodetska@gmail.com, ORCID 00000003-0265-5505.

Khanyk T. Ya. - external postgraduate student of the Department of Traumatology and Orthopedics, Kharkiv National Medical University, Kharkiv, Ukraine. E-mail: taras.hanyk@gmail.com, ORCID 0000-0003-1656-6239.

ISSN 2312-0967. Фармацевтичний часопис. 2020. № 4 